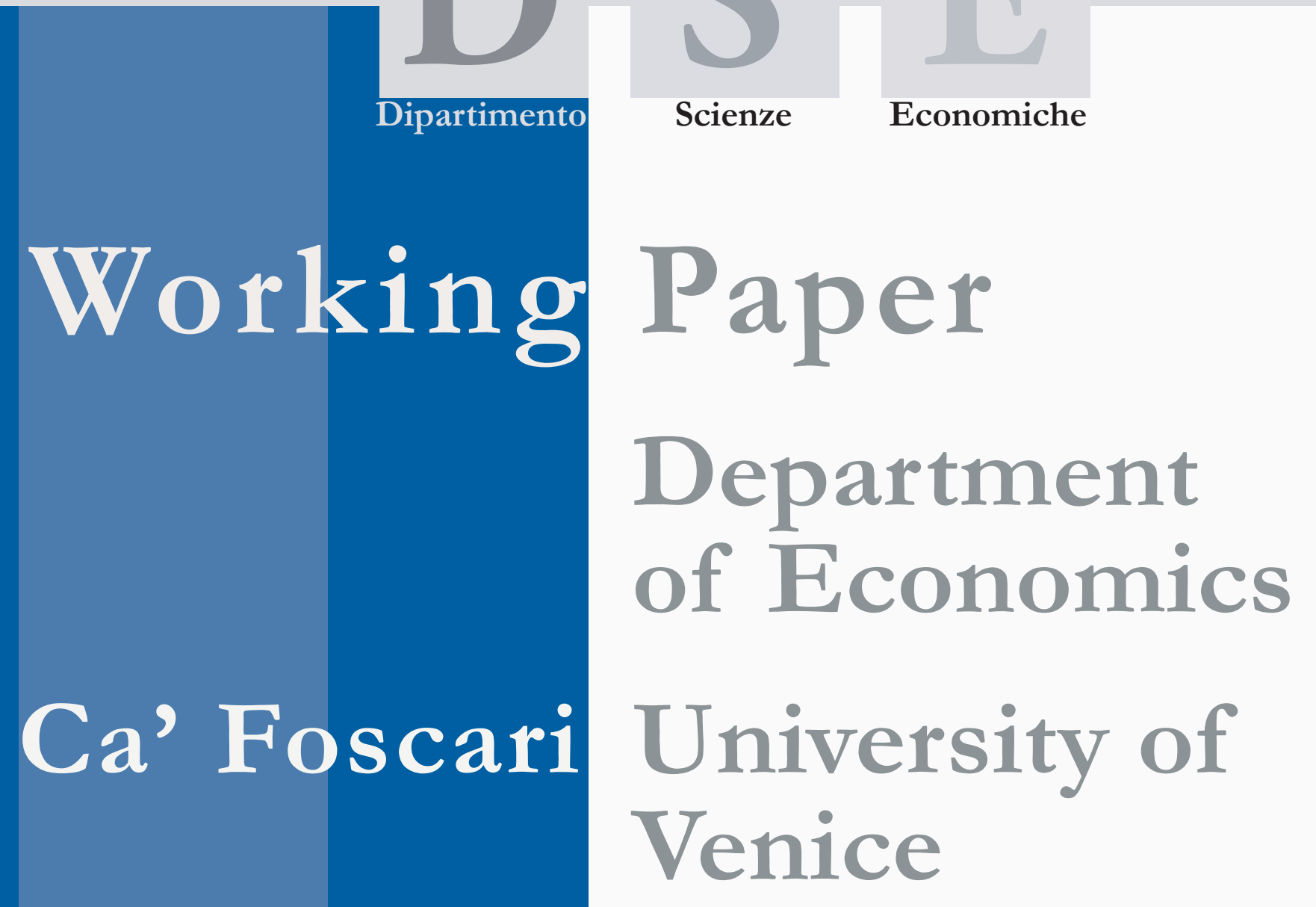

Andrew Holmes

John Ryan

The Individual Impacts of Commoditization 


\title{
The Individual Impacts of Commoditization
}

\author{
Andrew Holmes \\ Partner, Paricint \\ John Ryan \\ Cass Business School and Heilbronn Business School
}

First Draft: May 2008

\section{Abstract}

The process of commoditization has now entered its most significant phase. White collar work long the preserve of the educated elite is now going undergoing a significant transformation as it starts to commoditize.

The principal impacts on the white collar employee include:

- One company, but many owners as the impacts of foreign ownership, buy-outs by private equity and takeovers by rivals continue to change the pattern of company ownership as well as employment. Few of us can expect to remain within a single company that retains its ownership for a lengthy period of time and with this comes additional uncertainty and insecurity

- $\quad$ The potential for most if not every white collar job being at risk from commoditization; perhaps not now, but certainly in the future. Remember, any job that can be codified is potentially at risk

- An increase in low level, routine work at the expense of the intrinsically interesting work most white collar workers have come to expect. This does not necessarily mean that work will be any less pressured. Evidence is pointing to the intensification of routine white collar work which is becoming more demanding not less.

- $\quad$ The loss of an obvious career path making it much harder to navigate through your working life. This is further compounded by the weakening of the relationship between education and employability which has until very recently been central to a successful career

- $\quad$ Economic instability and income stagnation as the China Price moves to the white collar labour market.

\section{Keywords}

Commoditization, employment

\section{JEL Codes}

$\mathrm{J} 2$, LO

Address for correspondence: John Ryan

Cass Business School Cass Business School, City University, London 106 Bunhill Row, London EC1Y 8TZ

T: +44(0)20 70405165

F: +44(0)20 70408700

e-mail: jmtryan@aol.co.uk

This Working Paper is published under the auspices of the Department of Economics of the Ca' Foscari University of Venice. Opinions expressed herein are those of the authors and not those of the Department. The Working Paper series is designed to divulge preliminary or incomplete work, circulated to favour discussion and comments. Citation of this paper should consider its provisional character.

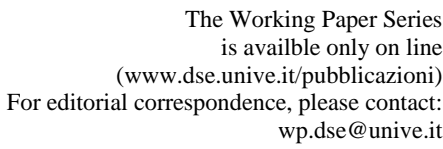

The Working Paper Series

wp.dse@unive.it
Department of Economic

Ca' Foscari University of Venice

Cannaregio 873, Fondamenta San Giobbe

30121 Venice Italy

Fax: ++39041 2349210 


\section{One company but many owners}

The past few years has witnessed a massive increase in the levels of takeovers and acquisitions. The number of mergers and acquisitions in 2006 exceeded the highest annual figure on record, which was at the height of the Dot Com mania in 2000. Back then the deals totalled \$3,332 billion ${ }^{1}$ and by the end of 2006 this figure had reached a record $\$ 3,760^{2}$. Not only are the number of deals greater now greater, but their size is also increasing with a larger number over $\$ 10$ billion and the average deal coming in at around \$200 million. Most sectors are targeted and indeed most companies these days seem to present viable opportunities for takeover. Deals are also increasingly driven by the Private Equity houses such as Texas Pacific Group and Kohlberg Kravis Roberts who are becoming increasingly bold in their targets.

Taking small companies private and improving them is generally thought to be a good thing because it shakes up the often complacent management team. However, many are now chasing the largest companies in the attempt to gain significant returns. Companies such as Alliance Boots the global wholesale/retail drug supplier (which has now been sold to Kohlberg Kravis Roberts and Co. for \$29.4 billion ${ }^{3}$ ), Sainsbury, one of the UK’s largest supermarkets, EMI the record company, Qantas the Australian airline and the London Stock Exchange have all been targets. Another interesting trend is the increasing number of hostile bids which is making life difficult for the target companies and forces them to take very costly actions to defend themselves.

Unions are becoming increasingly unsettled at the scale of private equity especially in terms of their impact on the livelihoods of their members and intend to publish their own data, which will contest that of the private equity houses who claim to create, not destroy jobs. Typical of the complaints made by the unions are those associated with the Automobile Association (AA) in the UK. Staff and 
unions have expressed concerns that core services are being cut in order to maximise the profits of Permira and CVC the private equity owners. Once a mutual owned by its members, the AA was bought in 1999 by Centrica the multinational company before being sold to Permira and CVC in 2004. If the company is sold in 2008 it may net the equity partners $£ 1.75$ billion in profits. To achieve this, the AA's 10,000 workforce has been cut by a third, which includes some 600 patrolmen ${ }^{4}$. No wonder than that many amongst union ranks believe private equity to be a cancer that must be stopped. In more recent moves the big Service Employees International Union has started researching and blogging about corporate buyout deals ${ }^{5}$ and in March 2007, union officials from 15 nations called on industrialised countries to impose greater regulation and are lobbying the Organization for Economic Cooperation (OECD) and other bodies such as the International Monetary Fund ${ }^{6}$.

Of course private equity has a role to play and if companies were well run in the first place, they would never be targets. It should be remembered that private equity companies will only take on a new acquisition if they can see value from the deal. And such value comes from four sources: earnings growth (which is revenue and/or margin driven); multiple expansion (of earnings multiples and hence valuation); hidden value (such as forgotten divisions or restructuring), and financial leverage ${ }^{7}$.

In parallel with this is the rise of the new conglomerates of the world that are equally hungry for a piece of the action. Many of the global powerhouses now hail from the emerging economies of the Far East, South America and Africa. Few commentators on free trade would have predicted such a rise would ever occur and now companies such as Hyundai and Cemex are becoming the next global employers who are replacing the household names most of us have grown up with. Today there are at least 25 world-class multinationals that hail from the emerging economies and this is 
expected to increase to over 100 within the next ten years ${ }^{8}$. Like all other multinationals these emerging leaders are keen to expand into new markets, takeover western businesses and to build their brands into something that is as recognisable as Coke and General Motors. They are making steady progress. For example French electronics giant Thomson was purchased by Chinese consumer electronics company TCL, Siemens Mobile was acquired by Taiwan's BenQ and German’s Grundig was acquired by the Turkish company Beko. In 2005 these emerging multinationals spent $\$ 42$ billion on takeover deals in Europe alone ${ }^{9}$. Take Mittal Steel, the Dutch listed company that is now the biggest steel company in the world. The company was built up by snapping up aging steel mills across the former Soviet Union and its satellite states, such as Poland, before negotiating the $\$ 4.5$ billion buyout of International Steel Group in 2004. Then in 2006 Mittal launched a successful hostile bid for the second largest steel group, Arcelor which it purchased for \$34 billion. What was significant about this deal is that it represented the consolidation between the No 1 and No 2 players in the market which is a break from the standard approach which involves the largest companies snapping up the smallest ones ${ }^{10}$.

So what does this mean for the average worker? First it generates a lot more uncertainty within the workforce because all mergers and acquisitions expect to produce significant savings from the synergies created by the joining together of two companies. Such savings are primarily associated with a reduction in the number of employees, which can be in the tens of thousands. For example the takeover of ABN Amro, the Dutch bank, by Barclays one of its UK rivals will result in a reduction of 12,800 jobs and the offshoring of a further 10,800 to low cost countries such as India ${ }^{11}$. As more companies consolidate there will be a continued downward pressure on headcount and increased levels of uncertainty. Second, staff will have to get used to regular changes of ownership. On face value this shouldn't create too much problem, as once the headcount reductions that typically follow any acquisition have ended it will be back to business as usual. Indeed many acquired companies are left alone to just deliver the numbers. However any shift in ownership 
creates turbulence, be it in changes in leadership and the various layers of management across the organization, in process, location and systems and even culture. Newly merged companies tend to battle it out between the legacy businesses and the culture clash that results often lasts a considerable amount of time, and much longer than most companies believe it should. So although there may be some short-term uncertainty about the immediate loss of a job, the uncertainty does not end there, as staff will feel uneasy about their medium and long-term futures. With new management also come new options to be explored, such as outsourcing and offshoring. Private equity ownership also creates medium term uncertainty because few if any will hold on to their acquisition for long. Apart from a very few exceptions, a private equity house will have its exit strategy defined at the time of purchase, so don’t expect there to be certainty once the acquisition has completed.

\section{All white collar jobs at risk}

Ever since downsizing hit the corporate world in the1990s we have been told that we should not expect to have a job for life. And although it has taken a long time to adjust to the changes which downsizing heralded, many of today's workforces have finally come to accept that mantra. It is certainly true that few of us can really expect to have a job for life in the same way the Boomer Generation had and many of us change our careers a number of times over the course of a 30-40 year working life. So what's new and why is this something we need to worry about? First job churn is increasing at a much higher rate than in the past. Despite the massive layoffs that came with the downsizing projects it wasn't long before many corporations re-stabilized and continued much as before - just a bit leaner and meaner and with a generally much less committed workforce. When it comes to job churn, we usually assume that it is the West that is losing their jobs at the fastest rate as they move to the cheaper economies of the East. However this is not the case. When the global job market is taken into account and particularly its growth, we find that although the global economy continues to expand there is little or no growth in actual employment. Jobs are being lost everywhere and even in China. At the same time global unemployment is rising especially amongst 
the younger workers. Job churn is also affected by the ownership changes discussed above. As the revolving door of ownership continues to turn the level of job churn and job losses will continue to mount as the new owners seek efficiencies and the subsequent reductions in headcount which follows. Second, as the combined impacts of an increasingly educated global workforce and advancements in technology play out, more of what we class as solid white collar work will come under the scrutiny of commoditization.

Alan Blinder of Princeton University has attempted to place a figure on the number of American jobs that could potentially be offshored, and in doing so has highlighted a whole raft of jobs that already are or could become commoditized. His main argument is that it is the occupation, not the industry that can be offshored and those jobs which require no physical contact are most at risk ${ }^{12}$. Blinder breaks the total United States jobs market into four categories ${ }^{13}$ :

- Category I - Highly Offshorable. These are the jobs that do not require the worker to be physically close to a specific work location or in the United States and encompasses 59 occupations and some 8.2 million workers $^{14}$. Typical occupations include computer programmers, actuaries, statisticians, technical writers, insurance claims processing clerks and economists $^{15}$

- Category II - Offshorable. These are the jobs that need to be physically close to the work unit but do not have to be located in the United States and in this case include 151 occupations and 20.7 million workers ${ }^{16}$. Typical occupations in this category include tax preparers, electrical engineers, chemists, procurement clerks and medical scientists ${ }^{17}$

- Category III - Non-offshorable. These are the jobs which have to physically close to the work unit and must also be carried out somewhere within the United States and coveres74 occupations and 8.8 million workers ${ }^{18}$. Typical occupations which fall into this category include broadcast news analysts, producers and directors, aerospace engineers, purchasing managers and training and development managers ${ }^{19}$ 
- Category IV - Highly non-offshorable. These are the jobs where the person needs to be close to a specific work location in the United States and encompasses 533 occupations and 92.6 million workers $^{20}$. Typical occupations which fall under this category include health and safety engineers, advertising sales agents, business operations specialists and nurses ${ }^{21}$.

His analysis suggests that between 22 and 29 per cent of all United States jobs could be offshored and the same is probably true of many of the industrialised nations of the West. So, just because the work is well paid today there is no guarantee that it will continue to be well paid in the future.

\section{Fewer interesting jobs, but demanding all the same}

It is clear that the commoditization of white collar work will mean that there will be fewer opportunities for employees to genuinely exercise their intellect within the average workplace. Indeed, whilst we are being led to believe (mainly by our governments it has to be said and perhaps the HR departments of many corporations) that the demand for knowledge work will increase dramatically; it appears that there is little evidence to support this assertion. The largest growth in jobs is at the lower end of the service economy and most people will continue to work in occupations that require low levels of education and training; some 70 per cent of the workforce in fact $^{22}$. Indeed, it appears that the proportion of workers who hold qualifications above those required for the jobs they hold is growing, not shrinking. This has increased from around 30 per cent in 1986 to nearly 40 per cent in $2002^{23}$ and will undoubtedly go much higher as the effects of commoditization play out and an increasing number of highly qualified workers flood the job market. Such a mismatch impacts the quality of the working experience for the well educated and ultimately suppresses income ${ }^{24}$. It also forces more and more of the less qualified to the periphery of the economy with all the issues and problems this brings. Some of this peripheral work will entail serving the richer cohorts of society and this is already happening with the return to the servant class who clean floors, pack bags and cook our meals ${ }^{25}$. As the cash rich but time poor executives find it increasingly difficult to cope with the domestic side of their lives, they are turning in greater 
numbers to the time rich and cash poor to carry out these basic activities. All this and the other evidence suggests that the knowledge economy has failed to deliver on its promises as most jobs are de-skilled as managers exercise tighter controls over the labour processes ${ }^{26}$.

Technology is fantastic at eliminating the need to think and equally good at forcing us to follow a set of computer driven processes (no matter how bad they might be and no matter how much they tie an organization up in knots). Whilst job quality may well reduce over time the demands placed upon workers seems to be increasing. People are working more intensely than ever before and experiencing greater mental strain and higher levels of exhaustion ${ }^{27}$. The reasons for the increasing demands placed upon white collar workers are varied and are not purely related to the introduction of new technology, although this does have a major part to play. A secondary factor associated with technology, which also impacts the level of demand placed upon employees, is the impact of workflow. For those people who work within a call centre this will be more than familiar to them. The call routing technology used within call centres acts as a modern day production line in which different types of calls are routed to the operatives one after another, so that as one call is finished the next one starts ${ }^{28}$. This creates significant demands on the employee and it is well known that Indian call centre operatives suffer from stress and burnout because of the demanding nature of their work, even though they follow predefined scripts and procedures when dealing with the call. As technology becomes more sophisticated and as work becomes more codified and commoditized it doesn't stretch the imagination too far to see how the same increase in demand can be placed on other white collar workers.

Another factor which has increased the demands of work has been the rapid shift to the service economy which has entailed a greater number of white collar workers' work being dictated by the customer. ${ }^{29}$ Workers need to respond to customer needs as they arise and to cater for that demand employers will roster their staff accordingly so that there is little downtime. They will also increase 
the demands on their staff through multi-skilling so that when demand is lower in one area, they can be used to meet the demands in another. Nurses in the UK have seen this first hand with the widening of their role to encapsulate supervisory, management and even minor surgical activities in addition to their basic nursing tasks ${ }^{30}$.

Employers also have another trick up their sleeve which can result in greater demands being placed upon their workers and that is the ability to monitor the work as it is executed. One of the most significant benefits which commoditization brings to the employer is transparency of work based activity. Commoditization is capable of making previously invisible work visible and through this facilitates its monitoring by management, who are able to assess an individual's effort and contribution more precisely. And finally as employers gain the upper hand in the ongoing struggle between themselves and their workers, it is likely that the checks and balances provided by organised labour will diminish. When faced with the stark choice between keeping jobs which are more demanding and which may pay less or seeing them pass over to cheaper labour elsewhere, many unions find they have little choice but to accept the harsh realities of the changing world of work. In the UK for example, the proportion of unionised workers fell by 0.6 per cent in 2006 to 28.4 per cent, its biggest drop for eight years ${ }^{31}$. This is of course even worse for the white collar worker, who very often is without the support of a union - only 16.6 per cent of private sector workers in the UK are unionised ${ }^{32}$. The ability to dictate terms to employees is one reason why WalMart would rather close its stores and give up business than cede control to the unions. For example in August 2004, a union was given authority to negotiate on behalf of the 190 staff at a store in Quebec, Canada. Ten months later the 130,000 square foot store was closed down and everyone lost their job ${ }^{33}$. Workers are increasingly finding that unions have little weight when addressing the impacts of globalization and commoditization.

Recent survey data supports the combined effects of all of the above and is suggesting that 
employees are working harder, faster and with increasing levels of tension than ever before and this is something that is increasingly reflected in most economies ${ }^{34}$. There is nothing to suggest that this will change over the foreseeable future, as the effects of technology, a surplus of intelligent employees and the need to compete against low cost competitors will continue to play out. And with these will come more demands on the average worker who, in order to remain economically viable over the course of their working life will have little choice but to pick up the pace.

\section{The loss of the traditional career path}

Things are undoubtedly changing in that traditional career paths are gradually disappearing. The obvious and previously strong link between education and long-term employability and career advancement is becoming much weaker. The significant investment in time, money and energy no longer has its obvious payback. Although education still remains a principal plank in the ability to compete and outsmart others who work within the knowledge economy, the sheer number of graduates available in the market makes this much harder and there are fewer guarantees of success. With 90 per cent of the world's scientists expected to be living in Asia by $2010^{35}$ even those who believe that following a career path in science or indeed engineering is a cast iron way of protecting themselves may be mistaken. The expectation that many of the emerging nations would take a long time to build the infrastructure necessary to generate a high-skilled workforce has proved to be wide of the mark. For example, although Singapore initially pursued a low-skilled strategy to economic advancement, it has since moved to a high-skilled agenda and within a comparatively short space of time has become the world's second most competitive nation ${ }^{36}$. This is not to say education is unnecessary, but longevity in one's career is no longer firmly linked to it ${ }^{37}$. Instead education will become a defensive mechanism which will be used to gain a seat at the employment table ${ }^{38}$. It may not, of course keep you there without a focus on continuous learning. To some extent we are already seeing some of this defensive stance with the increasing numbers of post graduate qualifications. Just as the direct correlation between education and employability is weakening the traditional 
career on which it was predicated is also disappearing. Apart from the small number of people who appear to be blessed by their organizations, career progression for the majority of workers is slowing. The global oversupply of labour which is increasingly educated creates the backdrop for white collar commoditization and the threat to the traditional career path most of us been expected to pursue. This exacerbates the self-esteem issue discussed at the beginning of the chapter, as it creates a massive disconnect between the expectations of the younger workforce and what turns out to be reality. Fewer can expect the glittering career promised them when they were young. Most will end up in mediocre jobs with few real prospects for advancement. But there is more to this issue than meets the eye as there are some other factors which are affecting the traditional concept of a career path. First, the flattening of organizational hierarchies which followed the downsizing of corporations has meant that there are fewer layers to pass through to get to the top. That's fine if there are plenty of opportunities at the top of the organization, but that is rarely the case. Without the perceived progression that comes with deep corporate structures staff will be left at the same position for long periods of time which may not be good for them or the business without some creativity on the company's part to keep them engaged. Second, technology as we saw above allows the flow of work to be more effectively controlled and as it continues to become more sophisticated and capable of subsuming business processes it is likely that there will be less need for supervisors. Third, as the impacts of market consolidation through mergers and acquisitions continue to play out, there will be fewer positions to fill. When two similar companies come together there is no need for two CEOs, two marketing departments and so one, so duplicate positions and functions disappear along with the opportunities for career progression. Fourth the hollowing out of the corporation, is also reducing the career path for many workers. Eliminating the bulk of your finance, IT, HR, legal and any other function for that matter, means once again that there are fewer opportunities for advancement. With a single outsource organization running the finance or HR activities for many other companies, those finance and HR professionals who would have previously worked in-house, no longer have a job. And finally the impact of commoditization on job classes itself will also limit 
the opportunities for a typical career as work goes overseas and as technology and general changes in the nature of work remove the need for certain jobs. In summary then, the notion of a mapped out career path continues to be replaced with a random walk with advancement no longer predicated on character and conduct ${ }^{39}$.

\section{Economic instability and income stagnation - the China Price moves to white collar labour}

One of the central drivers of commoditization is price competition. As soon as price becomes the primary factor for negotiation then you have been commoditized. The ability to differentiate yourself from the millions of other graduates and white collar workers is hard and when we consider that the billion plus populations of India and China are beginning to compete for the high-skilled work that has been the preserve of America and Europe, it is easy to see how white collar and skilled work will be subject to long-term price competition. According to some commentators this is leading us towards a high-skill, low-wage economy ${ }^{40}$. Others believe that the doubling of the global labour pool from 1.46 billion to 2.93 billion when China, the ex-Soviet countries and India are included will create the biggest challenge since the Depression of the $1930 \mathrm{~s}^{41}$. The economic impacts of commoditization on the middle classes are already showing up in the stagnation of incomes and the increasing fragility of household balance sheets. Even when we strip out peoples’ desire to live beyond their means and to emulate their favourite celebrities, the number of bankruptcies is increasing dramatically as workers find themselves on a path of downward mobility and struggle to make ends meet on a lower income. Although economies continue to grow and create jobs, many of these as we have seen do not require highly skilled individuals to execute them. There is also no evidence to support the assertion that a low inflation environment leads to jobs and income growth, in fact the opposite appears to be true ${ }^{42}$. Add to this an increase in the share of workers who find themselves without work, which has increased to levels not seen since recession of the early 1980s and you can see that there are problems ahead as the unemployed increase the 
downward pressure on incomes ${ }^{43}$.

Another important aspect about earnings is that incomes now rise and fall more sharply than ever before and such volatility is more of an issue than income inequality ${ }^{44}$. Evidence for this comes from the Panel Study of Income Dynamics (PSID) which is an American survey that has been tracking thousands of families each year from the late $1960 \mathrm{~s}^{45}$. What this survey shows is by how much a family's income can rise and fall and how the range between the lowest and highest has risen over the recent past. For example the difference between the highest and lowest in the 1970s was 43 per cent (in other words the lowest income for a given year was 43 per cent of the highest) whilst in the period 1993-2003 this had dropped to 25 per cent, itself a significant reduction from the near 36 per cent difference that was typical of the previous decade. The trend is clearly downwards. The fact that people are doing well one year and badly the next is missed in the annual snapshots of income and therefore hides the true levels of volatility that exist in many households ${ }^{46}$. This instability in income is at an all time high and is now five times greater than it was in the 1970s. Like every other trend associated with commoditization, it is not only the blue collar workers who are having to cope with the issue, as many white collar workers are now facing the rollercoaster ride of income volatility from which they thought themselves immune ${ }^{47}$, and which they believed they had been protected against by a solid education. Some of the increased volatility and its associated insecurity will undoubtedly come from the changes in ownership which not only result in a loss of income through redundancy, but also a reduction in upward mobility. Other sources will include outsourcing and offshoring which always result in a lowering of income.

The China Price which is so expertly used by Wal-Mart to suppress wages and ensure their suppliers can match their price expectations exerts a powerful downward pressure on incomes. In the recent past this has been restricted to the manufacturing sector, but as the full force of the global workforce is felt, the China Price will start to invade the world of the middle class white collar 
worker. As a result real income volatility may increase and real income growth may become a thing of the past for many. When there is someone out there who is both willing and able to do your job, but for a fraction of the price, what do you do? You do what Wal-Mart's suppliers do, you conform and accept a lower income or you fold and take your chances elsewhere. It's often that binary. The problem is of course that we would all rather have a stable income than no income at all and the unfortunate thing with commoditization is that it makes everything far more unstable for us all. This is of course extreme but the oversupply of graduates means that, as we saw above, all white collar jobs are potentially at risk from commoditization and the longer-term impacts of this may be significant. 


\section{References}

${ }^{1}$ Armistead, L., and Rushe, D., (2006), Boom time as M\&A deals reach an all-time record, The Sunday Times, Business, November 19, p 3-1

${ }^{2}$ Rushe, D., (2006) All aboard the M\&A express, The Sunday Times, December 31, p 3-5

${ }^{3}$ Craven, N., (2007) KKR, Pessina win Boots chain with £11.1 B bid, National Post, April 25, p FP16

${ }^{4}$ Calvert, J., and Ungoed-Thomas, J., (2007), AA ‘cutting services’ to boost profits, The Sunday Times, June 24, p 1-10

${ }^{5}$ Sender, H, and Lueck, S., (2007), Tax plan adds to the pressure on buyout firms, The Wall Street Journal, June 16-17, P

A1

${ }^{6}$ Arnold, M., (2007), Unions vow to fight the 'cancer’ of hedge funds, Financial Times, March 17-18, p 6

${ }^{7}$ Sanderse, M (2007), Private Equity and Transport: Alchemist or turbo charged investors, Morgan Stanley, p 13

${ }^{8}$ Agtmael, A., (2007), The emerging markets century, (New York: Free Press), p 15

${ }^{9}$ Ibid, p 25

${ }^{10}$ Rushe, D., (2006) All aboard the M\&A express, The Sunday Times, December 31, p 3-5

${ }^{11}$ Thal, P., et al., (2007), Scepticism greets Barclay’s figures, Financial Times, 24 April, p 22.

${ }^{12}$ Blinder, Al., (2007), How many jobs might be offshorable? Princeton University, CEPS Working Paper No. 142, March 2007, p 5

${ }^{13}$ Ibid., p 18

${ }^{14}$ Ibid., p 19

${ }^{15}$ Ibid., pp 38-39

${ }^{16}$ Ibid., p 19

${ }^{17}$ Ibid., pp 39-42

${ }^{18}$ Ibid., p 19

${ }^{19}$ Ibid., pp 41-43

${ }^{20}$ Ibid, p 19

${ }^{21}$ Ibid., p 43

${ }^{22}$ Agtmael, A., (2007), The emerging markets century, (New York: Free Press), p 65

${ }^{23}$ Green, F., (2006), Demanding work: the paradox of job quality in the affluent economy, (New Jersey: Princeton University Press), pp 40-41

${ }^{24}$ Ibid, p 41

${ }^{25}$ Ibid, p 6 
${ }^{26}$ Ibid, p 35

${ }^{27}$ Ibid, p 1

${ }^{28}$ Ibid, p 70

${ }^{29}$ Ibid., p 6

${ }^{30}$ Ibid, p 72

${ }^{31}$ Smith, D., (2007), Workers count cost of a global labour flood, The Sunday Times, April 29, p 3-4

${ }^{32}$ Ibid

${ }^{33}$ Fishman, C., (2006), The Wal-Mart effect, (New York: The Penguin Press), p, 48

${ }^{34}$ Green, F., (2006), Demanding work: the paradox of job quality in the affluent economy, (New Jersey: Princeton University Press),, pp 44-65

35 Brown, P., et al (2006, Towards a high-skilled, low-waged economy? A review of global trends in education, employment and the labour market, in Porter, S., and Campbell, M., (eds) Skills and economic performance, (London: Caspian Publishing), p 62

${ }^{36}$ Brown, P., et al (2006), Towards a high-skilled, low-waged economy? A review of global trends in education, employment and the labour market, in Porter, S., and Campbell, M., (eds) Skills and economic performance, (London: Caspian Publishing), pp 58-59

${ }^{37}$ Ibid, p 63

${ }^{38}$ Ibid, p 84

${ }^{39}$ Elliot, L, and Atkinson, D., (1998), The age of insecurity, (London: Verso), p 131

${ }^{40}$ Brown, P., et al (2006), Towards a high-skilled, low-waged economy? A review of global trends in education, employment and the labour market, in Porter, S., and Campbell, M., (eds) Skills and economic performance, (London: Caspian Publishing), p 73

${ }^{41}$ Freeman, R., (2007), The great doubling: The challenge of the new global labour market, in Edwards J., et al., (2007) [eds], Ending poverty in America, (New York: The New Press), p 55

${ }^{42}$ Elliot, L, and Atkinson, D., (1998), The age of insecurity, (London: Verso), pp 238-239

${ }^{43}$ Hacker, J., (2007), The risky outlook for middle-class America, in Edwards J., et al., (2007) [eds], Ending poverty in America, (New York: The New Press), p 67

${ }^{44}$ Hacker, J., (2006), The great risk shift, (Oxford: Oxford University Press), p 2

${ }^{45}$ Hacker, J., (2007), The risky outlook for middle-class America, in Edwards J., et al., (2007) [eds], Ending poverty in 
America, (New York: The New Press), p 69

${ }^{46}$ Ibid

${ }^{47}$ Ibid, p 71 